\title{
Macrophage Migration Inhibitory Factor (MIF) Expression Increases during Myocardial Infarction and Supports Pro-Inflammatory Signaling in Cardiac Fibroblasts
}

\author{
Svenja Voss ${ }^{1,2,+}$, Saskia Krüger ${ }^{1,2,+} \oplus^{-}$, Katharina Scherschel ${ }^{2,3}{ }^{\oplus}$, Svenja Warnke ${ }^{1}$, \\ Michael Schwarzl 1,2 , Benedikt Schrage ${ }^{1,2}$, Evaldas Girdauskas ${ }^{2,4}$, Christian Meyer 2,3, \\ Stefan Blankenberg ${ }^{1,2}$, Dirk Westermann ${ }^{1,2}$ and Diana Lindner ${ }^{1,2, *(\mathbb{D}}$ \\ 1 Clinic for General and Interventional Cardiology, University Heart Center Hamburg, University Hospital \\ Hamburg-Eppendorf, 20246 Hamburg, Germany; Svenja.voss@yahoo.com (S.V.); s.krueger@uke.de (S.K.); \\ s.warnke@uke.de (S.W.); m.schwarzl@uke.de (M.S.); b.schrage@uke.de (B.S.); s.blankenberg@uke.de (S.B.); \\ d.westermann@uke.de (D.W.) \\ 2 Partner Site Hamburg/Kiel/Lübeck, DZHK (German Center for Cardiovascular Research), 20246 Hamburg, \\ Germany; k.scherschel@uke.de (K.S.); e.girdauskas@uke.de (E.G.); chr.meyer@uke.de (C.M.) \\ 3 Clinic for Cardiology_Electrophysiology, University Heart Center Hamburg, University Hospital \\ Hamburg-Eppendorf, 20246 Hamburg, Germany \\ 4 Clinic for Cardiovascular Surgery, University Heart Center Hamburg, University Hospital \\ Hamburg-Eppendorf, 20246 Hamburg, Germany \\ * Correspondence: d.lindner@uke.de; Tel.: +49-(0)40-7410-54864; Fax: +49-(0)40-7410-58862 \\ + Both authors contributed equally to this work.
}

Received: 1 December 2018; Accepted: 17 January 2019; Published: 23 January 2019

\begin{abstract}
Macrophage migration inhibitory factor (MIF) is a pleiotropic cytokine known to play a major role in inflammatory diseases such as myocardial infarction (MI), where its expression increases. Cardio-protective functions of MIF during ischemia have been reported. Recently, the structurally related MIF-2 was identified and similar effects are assumed. We wanted to further investigate the role of MIF and MIF-2 on inflammatory processes during MI. Therefore, we subjected mice to experimentally induced MI by coronary occlusion for one and five days. During the acute phase of MI, the gene expression of Mif was upregulated in the infarct zone, whereas Mif-2 was downregulated, suggesting a minor role of MIF-2. Simulating ischemic conditions or mechanical stress in vitro, we demonstrated that Mif expression was induced in resident cardiac cells. To investigate possible auto-/paracrine effects, cardiomyocytes and cardiac fibroblasts were individually treated with recombinant murine MIF, which in turn induced Mif expression and the expression of pro-inflammatory genes in cardiac fibroblasts. Cardiomyocytes did not respond to recombinant MIF with pro-inflammatory gene expression. While MIF stimulation alone did not change the expression of pro-fibrotic genes in cardiac fibroblasts, ischemia reduced their expression. Mimicking the increased MIF levels during MI, we exposed cardiac fibroblasts to simulated ischemia in the presence of MIF, which led to further reduced expression of pro-fibrotic genes. The presented data show that MIF was expressed by resident cardiac cells during MI. In vitro, Mif expression was induced by different external stimuli in cardiomyocytes and cardiac fibroblasts. Addition of recombinant MIF protein increased the expression of pro-inflammatory genes in cardiac fibroblasts including Mif expression itself. Thereby, cardiac fibroblasts may amplify Mif expression during ischemia promoting cardiomyocyte survival.
\end{abstract}

Keywords: myocardial infarction; macrophage migration inhibitory factor; MIF-2; cardiac fibroblasts; cardiac inflammation 


\section{Introduction}

Myocardial infarction (MI) remains one of the leading causes of death in Western society [1,2]. The acute interruption of blood flow to cardiac tissue leads to a demise of cardiomyocytes within the ischemic area [1,3]. Necrotic cardiomyocytes release a wide range of inflammatory molecules, which rapidly activate the innate immune response. This, further triggers the infiltration of the infarcted heart by leukocytes, leading to local inflammatory processes [3-5]. Recruited leukocytes remove dead cells and cellular debris via phagocytosis. This cardiac inflammatory response is thereby essential for cardiac repair and promotes scar formation by deposition of extracellular matrix proteins. However, aggravated cardiac inflammation can induce adverse tissue remodeling, which also impairs contractile function and can finally lead to the development of heart failure [3,6-9].

The macrophage migration inhibitory factor (MIF) is a 114 amino acid protein, structured as a trimer of identical subunits [10,11]. Since MIF is known as a pleiotropic inflammatory cytokine, it is involved in several inflammatory diseases such as MI, atherosclerosis, rheumatoid arthritis and sepsis [12-15]. First discovered as a T-cell-derived cytokine that inhibits the migration of macrophages [16-18], based on today's knowledge, MIF is expressed by immune and non-immune cells, including cardiomyocytes, and mediates the recruitment of mononuclear cells [18-22]. Its functions are mediated via the CD74/CD44 complex, but it is also described as a non-cognate ligand of the CXC chemokine receptors, CXCR2 and CXCR4 [23-25]. Recently, a second member of the MIF family was identified. Despite only $27 \%$ identity of the amino acid sequence, MIF and D-dopachrome tautomerase (D-DT, MIF-2) share a highly conserved structure. Similarly, it acts as homotrimer through the same cell surface receptors and is therefore designated as MIF-2 [26,27].

Elevated plasma levels of MIF are detectable in patients after acute MI for up to two weeks $[18,28,29]$ and can serve as a biomarker to predict infarct size. High MIF plasma levels on hospital admission are correlated with larger infarct size [30]. During a short ischemic/reperfusion setting, $\mathrm{Mif}^{-/-}$deficient mice showed increased infarct size, suggesting a cardio-protective function of MIF [31]. Given the contribution to inflammation during prolonged ischemia/reperfusion, MIF deficiency protects the heart and reduces infarct size [32]. However, in cultured cardiomyocytes, MIF expression is induced by hypoxia and redox stress which may further indicate a cardio-protective function $[18,20,33]$. Here, we investigated Mif and Mif-2 expression after myocardial infarction induced by coronary occlusion and identified cardiac fibroblasts as a more prominent cellular source of Mif within the infarct zone. In in vitro experiments, we applied various external stimuli to cardiomyocytes and cardiac fibroblasts to examine Mif expression and further its function regarding pro-inflammatory and pro-fibrotic signaling pathways.

\section{Materials and Methods}

\subsection{Animal Model}

Male C57BL/6J (B6) mice were used at the age of 8 to 10 weeks for the presented animal mouse model. Mice were anesthetized under artificial ventilation using isoflurane and buprenorphine was given as analgesic therapy. Access to the heart was gained via the third left intercostal space. MI was induced by permanent ligation of the left anterior descending artery (LAD) as described previously [34]. Sham mice underwent the same procedure except for coronary ligation. Mice were sacrificed after one day to analyze the acute phase (6 sham, $5 \mathrm{MI})$ or after five days to analyze the subacute phase $(8 \mathrm{sham}$, $11 \mathrm{MI})$. Hearts were removed and remote zone and border zone were separated from infarcted tissue. All tissue samples were snap frozen in liquid nitrogen and stored at $-80{ }^{\circ} \mathrm{C}$ for further analyses.

All investigations were approved by the local bioethics committee of Hamburg, Germany (G15/060) and conform to the Guide for the Care and Use of Laboratory Animals published by the US NIH (NIH Publication number 85-23, revised 1996). 


\subsection{Cell Culture}

The hearts of male wildtype C57BL/6J mice (10-12 weeks old) were used to obtain primary murine cardiac fibroblasts from the left ventricle (LV) as described previously [6]. The LV tissue was cut into pieces and digested in $0.1 \mathrm{mg} / \mathrm{mL}$ liberase (Roche, Grenzach-Wyhlen, Germany) under gentle shaking at $37^{\circ} \mathrm{C}$ for $10 \mathrm{~min}$. The cell-containing supernatant was collected and immediately stored on ice. The remaining tissue was further digested by addition of liberase for $10 \mathrm{~min}$. This procedure was repeated six times. In order to remove cell aggregates, the cell-containing supernatant was subsequently filtered through a cell strainer to obtain a single-cell solution. To remove the digesting buffer, cells were pelletized and resuspended in complete growth medium (DMEM containing 20\% fetal calf serum (FCS), $100 \mathrm{U} / \mathrm{mL}$ penicillin and $100 \mu \mathrm{g} / \mathrm{mL}$ streptomycin (Sigma-Aldrich, St. Louis, $\mathrm{MO}, \mathrm{USA}$ ) and cultured in a humidified atmosphere at $37{ }^{\circ} \mathrm{C}, 5 \%$ carbon dioxide and $95 \%$ air. For sub-culturing, cells were detached utilizing trypsin/EDTA (ethylenediaminetetraacetic acid) solution. To verify that we obtained cardiac fibroblasts, specific antibodies were used for positive and negative staining: cells were positive for collagen-I and negative for the myocyte marker desmin as well as the endothelial marker CD31, as described previously [6].

The HL-1 cells, a well-established murine cardiomyocyte cell line, were cultured as recommended in Claycomb medium (Sigma-Aldrich) supplemented with 10\% FCS, $100 \mathrm{U} / \mathrm{mL}$ penicillin, $100 \mu \mathrm{g} / \mathrm{mL}$ streptomycin, $2 \mathrm{mM}$ L-glutamine and $0.1 \mu \mathrm{M}$ norepinephrine (Sigma-Aldrich) [35].

Murine splenocytes were isolated from freshly removed spleen. To obtain a single-cell solution, the spleen was mashed through a cell strainer. The cell strainer was rinsed using phosphate-buffered saline (PBS) buffer, which was removed after centrifugation. The obtained cell pellet was resuspended in $3 \mathrm{~mL}$ PBS and layered onto $3 \mathrm{~mL}$ of Histopaque-1077 (Sigma-Aldrich) in a $15 \mathrm{~mL}$ conical tube and centrifuged according to the manufacturer's protocol. Supernatant was removed after centrifugation and the remaining cell pellet, containing the splenocytes, was collected in RPMI medium supplemented with $10 \%$ FCS, $100 \mathrm{U} / \mathrm{mL}$ penicillin and $100 \mu \mathrm{g} / \mathrm{mL}$ streptomycin (Sigma-Aldrich). Experiments with these cells were performed immediately.

\subsection{Simulated Ischemia, Mechanical Stretch and Cytokine Stimulation in Cell Culture Experiments}

Cardiac fibroblasts or cardiomyocytes were seeded in 12-well plates and grown to confluence before starving overnight in Dulbecco's modified eagle's medium (DMEM) containing 0.5\% FCS, 100 $\mathrm{U} / \mathrm{mL}$ penicillin and $100 \mu \mathrm{g} / \mathrm{mL}$ streptomycin (Sigma-Aldrich).

To induce ischemic conditions, cells received starving medium containing $4.5 \mathrm{~g} / \mathrm{L}$ L-glucose instead of D-glucose and were exposed to a gas mixture of $94 \%$ nitrogen, $5 \%$ carbon dioxide and $1 \%$ oxygen. Therefore, cells were placed into a modular incubator chamber (MIC-101, Billups-Rothenberg, Inc., San Diego, CA, USA), which was flushed with nitrogen and carbon dioxide using a flow rate ratio of 20 to 1, respectively until the final oxygen concentration of $1 \%$ was reached, detected by an oxygen sensor (Greisinger, Würzburg, Germany).

Mechanical stretch was applied to cardiomyocytes or cardiac fibroblasts using the Flexcell ${ }^{\circledR}$ FX-4000 ${ }^{\mathrm{TM}}$ Tension System (Dunn Labortechnik, Asbach, Germany). Therefore, cells were seeded in flexible-bottomed 6-well culture plates (Bioflex plates) coated with collagen-I (Flexcell Int. Corp., Burlington, NC, USA). When cells reached confluence, they were exposed to mechanical stretch regulated by vacuum pressure to deform the cultured cells. Mechanical tension was applied resulting in $10 \%$ elongation at a frequency of $1 \mathrm{~Hz}$ for $6 \mathrm{~h}$. Non-stretched control cells were seeded in the same flexercell plates without exposing them to mechanical stretch.

Stimulation was performed using a final concentration of $50 \mathrm{ng} / \mathrm{mL}$ recombinant murine MIF (R\&D Systems, Minneapolis, MN, USA) diluted in starving medium. Cardiomyocytes or cardiac fibroblasts were incubated with or without MIF protein for $24 \mathrm{~h}$ prior to RNA isolation. Furthermore, some cell culture samples were exposed to ischemic conditions and at the same time stimulated with MIF protein. In this case, MIF was diluted in starving medium containing $4.5 \mathrm{~g} / \mathrm{L}$ L-glucose instead of D-glucose. 
To induce pro-inflammatory or pro-fibrotic signaling, cardiac fibroblasts were starved overnight prior to stimulation using recombinant $10 \mathrm{ng} / \mathrm{mL}$ Tumor Necrosis Factor (TNF)- $\alpha$ (Peprotech, Hamburg, Germany) or $5 \mathrm{ng} / \mathrm{mL}$ transforming growth factor-beta (TGF)- $\beta$ (Peprotech), respectively. Recombinant proteins were diluted in starving medium, added to cardiac fibroblasts and incubated for $6 \mathrm{~h}$ prior to RNA isolation. Non-stimulated control cells were treated equally without addition of the recombinant proteins.

To examine activated leukocytes, freshly isolated splenocytes were used and activated with cell culture supernatant derived from ischemic cardiac fibroblasts for $24 \mathrm{~h}$. Non-stimulated control cells were incubated in starving medium.

\subsection{Histology and Immunofluorescence}

Immunohistological staining of infarcted hearts was performed as previously described [36]. Briefly, after routine processing for paraffin embedding, the hearts were cut in $4 \mu \mathrm{m}$ sections. Antigen retrieval was performed in a pressure cooker with citrate buffer $\mathrm{pH}$ 6. After incubation in $0.25 \%$ sudan black B (C.I. 26150, Roth) in 70\% ethanol and subsequent permeabilization in $0.2 \%$ triton X-100, sections were blocked in 3\% bovine serum albumin/tris-buffered saline (BSA/TBS) at room temperature for $1 \mathrm{~h}$. Primary antibodies (Table 1) were incubated overnight in 1\% BSA/TBS. After washing, incubation with the appropriate Alexa-labelled secondary antibodies and Alexa 633-labelled wheat germ agglutinin (WGA) (W21404, Life Technologies, Carlsbad, CA, USA) was performed. Sections were imaged with a Leica TCS SP8 confocal microscope and maximum projection images were created using the Leica LAS X SP8 software (Leica, Wetzlar, Germany).

Table 1. Antibodies for immunofluorescence detection.

\begin{tabular}{ccccc}
\hline Antibody & Species & Dilution & Company & Catalogue No.\# \\
\hline Primary antibodies & & & & \\
anti-MIF (FL-115) & Rabbit & $1: 100$ & $\begin{array}{c}\text { Santa Cruz } \\
\text { abcam }\end{array}$ & $\begin{array}{c}\text { sc-20121 } \\
\text { ab8101 }\end{array}$ \\
\hline Recti-MCP-1 (ECE.2) & & & & \\
\hline Secondary antibodies & & $1: 50$ & A10042 \\
anti-rabbit IgG (H + L) Alexa-568 & Donkey & $1: 500$ & Life technologies & A21208 \\
\hline
\end{tabular}

\subsection{RNA Isolation}

Total RNA from frozen cardiac tissue samples was isolated using QIAzol lysis reagent. Disruption of the tissue was achieved using pellet pestles followed by vigorous shaking for $10 \mathrm{~min}$. To obtain the RNA, chloroform was added. After centrifugation, the upper RNA-containing phase was collected and ethanol was added, followed by further purification using the miRNeasy mini kit (Qiagen, Hilden, Germany). To obtain total RNA from cells, RNeasy Mini Kit (Qiagen) was used according to the manufacturer's protocol. To avoid genomic DNA contamination within the isolated RNA from tissue or cells, DNase-I (Qiagen) was applied directly on the column during the purification protocol. The concentration of the resulting RNA was determined by measuring the absorbance at $260 \mathrm{~nm}$ using the Nanodrop 2000c spectrophotometer (Thermo Fisher Scientific, Waltham, MA, USA). RNA was stored at $-80{ }^{\circ} \mathrm{C}$ for further processing.

\subsection{Reverse Transcription and Gene Expression Analysis}

Reverse transcription of RNA was carried out using the High-capacity cDNA kit (Life technologies). An amount of $250 \mathrm{ng}$ total RNA from cell culture experiments or $1 \mu \mathrm{g}$ from tissue samples was reversely transcribed into cDNA for $2 \mathrm{~h}$ at $37^{\circ} \mathrm{C}$, followed by an inactivation step of $5 \mathrm{~min}$ at $85^{\circ} \mathrm{C}$. The resulting cDNA was further diluted to a final working concentration of $1.25 \mathrm{ng} / \mu \mathrm{L}$ for cell culture samples and $10 \mathrm{ng} / \mu \mathrm{L}$ for tissue samples. 
Real-time PCR was performed to assess gene expression for target genes using $5 \mu \mathrm{L}$ gene expression master mix (Life technologies) and $0.5 \mu \mathrm{L}$ gene expression assay (Table 2) purchased from Life technologies. A gene expression assay includes forward and reverse primers as well as the fluorescently labelled probe. A volume of $1 \mu \mathrm{L}$ of cDNA was used as template in a final volume of $10 \mu \mathrm{L}$. Each sample was analyzed in duplicates. Furthermore, the gene expression of $C d k n 1 b$ was determined as endogenous control to normalize the data using the formula $2^{-\Delta \Delta C t}$ and plotted as $\mathrm{x}$-fold to $C d k n 1 b$ as absolute gene expression. The relative gene expression data were additionally normalized using the formula $2^{-\Delta \Delta C t}$ and plotted as $x$-fold to the untreated control as described previously [37]. Real-time PCR was performed on a 7900 TaqMan system using the software SDS v2.4 (Applied Biosystems, Foster City, CA, USA).

Table 2. Gene expression assays purchased from Life technologies.

\begin{tabular}{ccc}
\hline Gene Symbol & Gene Name & Assay ID \\
\hline mActa2 & a smooth muscle actin & Mm00725412_s1 \\
mCcl2 & chemokine (C-C motif) ligand 2 & Mm99999056_m1 \\
mCd44 & cluster of differentiation 44 & Mm01277161_m1 \\
mCd74 & cluster of differentiation 74 & Mm00658576_m1 \\
mCdkn1b & cyclin-dependent kinase inhibitor 1B & Mm00438167_g1 \\
mCol1a1 & collagen type I, $\alpha$ 1 & Mm01302043_g1 \\
mCtgf & connective tissue growth factor & Mm00515790_g1 \\
mCxcr4 & chemokine (C-X-C motif) receptor 4 & Mm01996749_s1 \\
m Ddt $(M i f-2)$ & D-dopachrome tautomerase & Mm00515641_m1 \\
mMif & macrophage migration inhibitory factor & Mm01611157_gH \\
mproAdm & pro-adrenomedullin & Mm00437438_g1 \\
mTnf $\alpha$ & tumor necrosis factor $\alpha$ & Mm00443258_m1 \\
\hline
\end{tabular}

\subsection{Statistics}

Data are presented as box plots. All data were analyzed using GraphPad Prism 6 software (GraphPad Software, La Jolla, CA, USA). Statistical comparison of two groups was performed using the Mann-Whitney $\mathrm{U}$ test with $p$ values $<0.05$ considered statistically significant. More than two groups were compared using the Kruskal-Wallis test followed by Dunn's post-test with $p$ values $<0.05$ considered statistically significant. Pearson's correlation coefficients were computed by GraphPad Prism 6.

\section{Results}

\subsection{Expression of Macrophage Migration Inhibitory Factor is Upregulated in Mice After Myocardial Infarction}

Myocardial Infarction was induced in mice by permanent LAD ligation. Tissue samples were taken from the remote zone (RZ), the border zone (BZ) and the infarct zone (IZ) of the LV after the acute phase (1 day) and the subacute phase (5 days). The gene expression of Mif and Mif-2 was quantified and plotted as relative mRNA expression compared with sham operated animals. Figure 1A shows that gene expression of Mif was increased in the BZ and IZ during the acute phase after MI, however significant upregulation was determined only in the IZ (5.8 \pm 1.0 -fold). In contrast, the gene expression of Mif- 2 was decreased in the IZ ( $0.5 \pm 0.2$-fold). The upregulation of Mif in the IZ returned to basal levels after 5 days ( $1.5 \pm 0.4$-fold), whereas Mif-2 expression remained decreased 5 days after MI. 


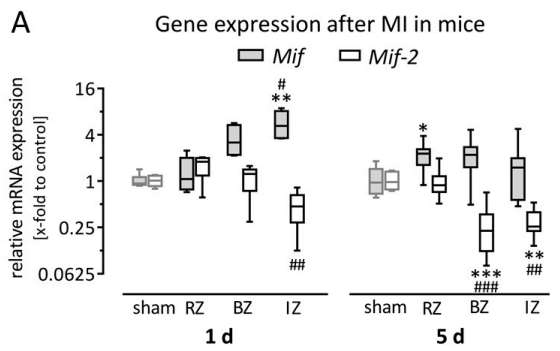

Correlation between Mif and $C c 12$ or Mif and Tnf- $\alpha$
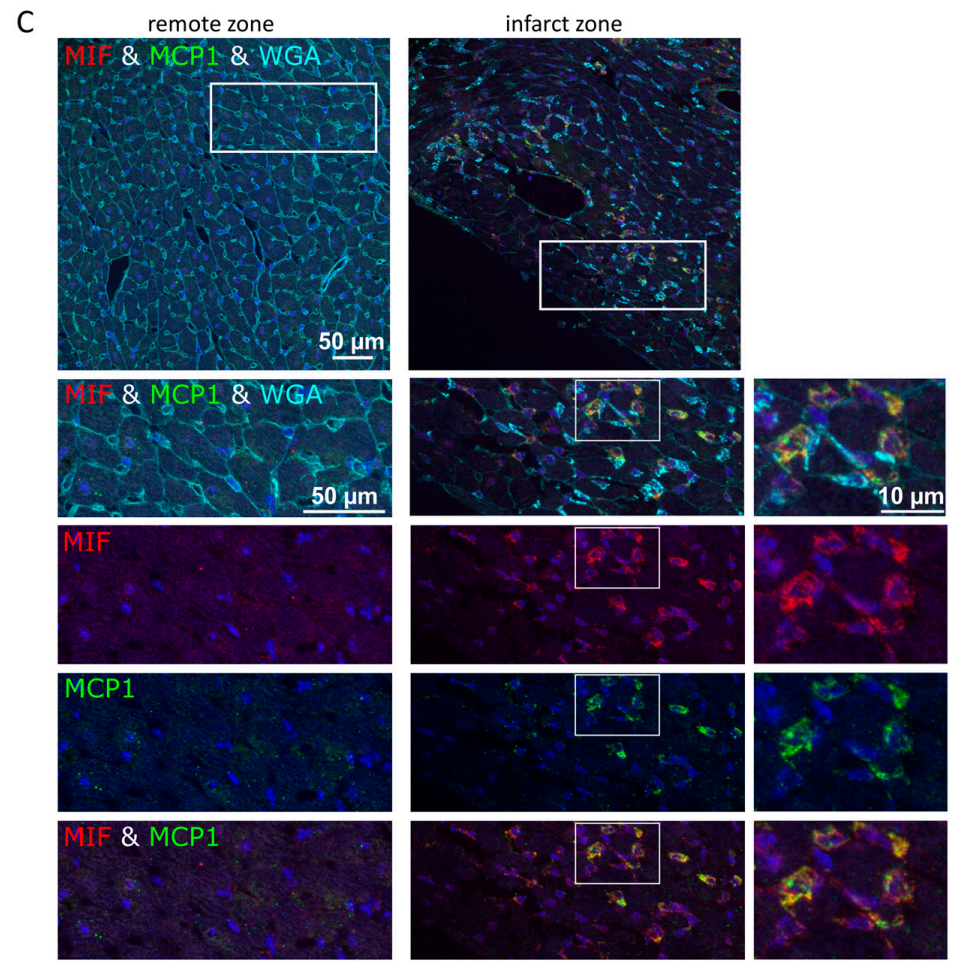

Figure 1. Mif and Mif-2 expression is oppositely regulated in mice after Myocardial infarction (MI). (A) MI was induced in mice by permanent coronary ligation. Gene expression of Mif and Mif-2 was quantified in left ventricular (LV) tissue samples collected from the remote zone (RZ), border zone (BZ) and infarct zone (IZ). Gene expression in the IZ was oppositely regulated for the two genes. While Mif was significantly increased during the acute phase (1 day) after MI, Mif-2 gene expression was significantly decreased. However, 5 days after MI, Mif gene expression returned to basal levels, whereas Mif-2 expression remained decreased. (B) Gene expression of Ccl2 and Tnf- $\alpha$ was quantified in LV tissue samples collected 1 day after MI. Gene expression of Mif is plotted on the x-axis while Ccl2 and $T n f-\alpha$ are plotted on the $y$-axis. Data collected from the IZ are shown as an asterisk, from the BZ as open squares and from the RZ as filled circles. Mif expression highly correlated to the expression of $C c l 2$ and $T n f-\alpha$. (C) Immunofluorescent staining of the RZ and the IZ of a cross section 1 day after MI is shown. The WGA staining was used to visualize the structural integrity of cardiac tissue and revealed a disarranged myocardial architecture within the IZ. Protein expression of MIF (red) and MCP-1 (green) are visible at higher magnifications. While no MIF expression and very low MCP-1 expression were determined in the RZ, both cytokines are highly expressed in the IZ. Furthermore, the overlay of the co-staining (yellow) revealed that both cytokines are co-localized in the same cells. Gene expression levels are shown as relative mRNA expression ( $\mathrm{x}$-fold to sham operated mice) using the formula $2^{-\Delta \Delta C t}$ and presented in box plots ( $\min$ to max). Gene expression data represent $6-8$ sham operated mice and 5-11 mice with MI. Scale bar represents $50 \mu \mathrm{m}$ or $10 \mu \mathrm{m}$. ${ }^{*}$ significantly different compared with sham operated mice. ${ }^{*} p<0.05$; ${ }^{* *} p<0.01$; ${ }^{* *} p<0.001$; ${ }^{* * *} p<0.0001$; \# significantly different compared with remote zone, \# $p<0.05$; \#\# $p<0.01$; \#\#\# $p<0.001$. 
Additionally, gene expression of the pro-inflammatory markers $C c l 2$ and Tnf- $\alpha$ was determined, representing the inflammation process during the acute phase after MI. Using linear regression, the gene expression of both genes was plotted against Mif expression 1 day after MI. As shown in Figure 1B, the gene expression of Mif highly correlates with the expression of $C c l 2(r=0.8678)$ and Tnf- $\alpha$ $(r=0.7481)$. To verify these mRNA data, immunofluorescence staining of cardiac tissue collected 1 day after MI was performed. As shown in Figure 1C, the myocardial architecture was clearly disorganized within the infarct zone, demonstrated by WGA staining. Furthermore, protein expression of MIF (red) and MCP-1 (green) was increased within the infarct zone compared with the remote zone during the acute phase (1 day) after MI. The overlay (yellow) after the co-staining revealed that both cytokines are expressed in the same cells.

3.2. Gene Expression of Mif Receptors Cxcr4 as Well as Cd74/Cd44 Was Increased after Myocardial Infarction as a Result of Recruited Leukocytes

The cell surface receptors CXCR4 and the heterodimer CD74/CD44 bind MIF and MIF-2. As illustrated in Figure 2A, CD74 and CD44 form a heterodimer in which CD74 is the virtual binding partner and CD44 the signaling component. First, we determined the basal expression levels of all three genes in healthy cardiac tissue. As shown in Figure 2C, Cxcr4 revealed very low gene expression (0.0027 \pm 0.0002 -fold to $C d k n 1 b)$, whereas Cd74 (1.0 \pm 0.1 -fold to $C d k n 1 b)$ and $C d 44$ (0.19 \pm 0.01 -fold to $C d k n 1 b$ ) are well expressed in cardiac tissue. Next, we analyzed whether their gene expression is upregulated after MI in the infarct zone 1 day and 5 days after LAD ligation. To analyze their relative regulation, we plotted the results as relative mRNA expression compared with sham operated animals in Figure 2B. The gene expression levels of all three cell surface receptors were highly increased in the infarct zone 1 day, as well as 5 days after MI.

To examine the cause of increased receptor expression within the IZ, we analyzed the basal gene expression of $C x c r 4, C d 74$ and $C d 44$ in different cell types. In Figure 2D, we plotted the ratio of the gene expression levels within the distinct cell type and the healthy LV tissue. Therefore, the gene expression of each receptor was normalized to its basal expression level in healthy cardiac tissue, shown in Figure 2C. Cardiomyocytes and cardiac fibroblasts did not express the MIF receptor Cxcr4 but did express both receptor components for the heterodimeric MIF receptor $C d 74 / C d 44$. As the ratio of $C x c r 4$ expression in leukocytes is higher than one, those cells are the main contributor to the Cxcr4 expression in LV tissue. Therefore, the infarct zone, representing inflamed cardiac tissue, showed highly increased Cxcr4 expression in the acute ( 1 day) and subacute ( 5 days) phase after MI. Furthermore, $C d 74$ as well as $C d 44$ were expressed more highly in leukocytes than in healthy LV tissue. Therefore, the increased expression of $C d 74$ and $C d 44$ within the infarct zone is a result of recruited leukocytes. 
A

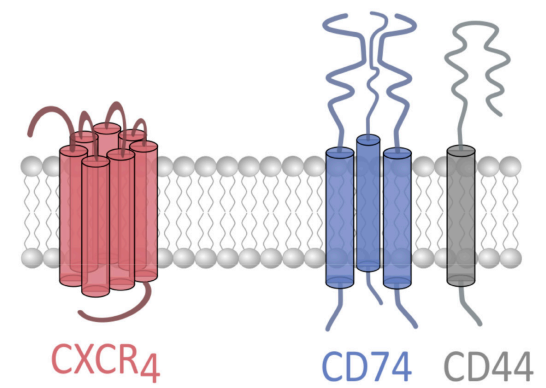

C

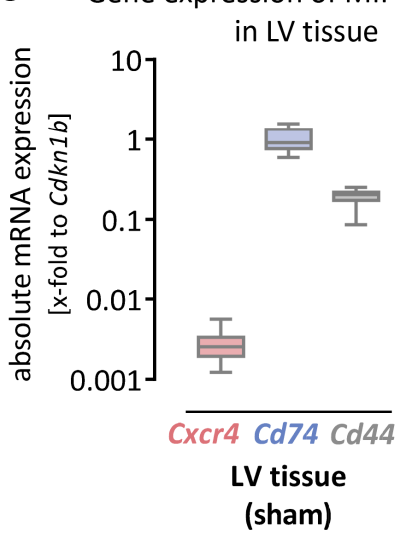

B

Gene expression of MIF receptors after MI in mice

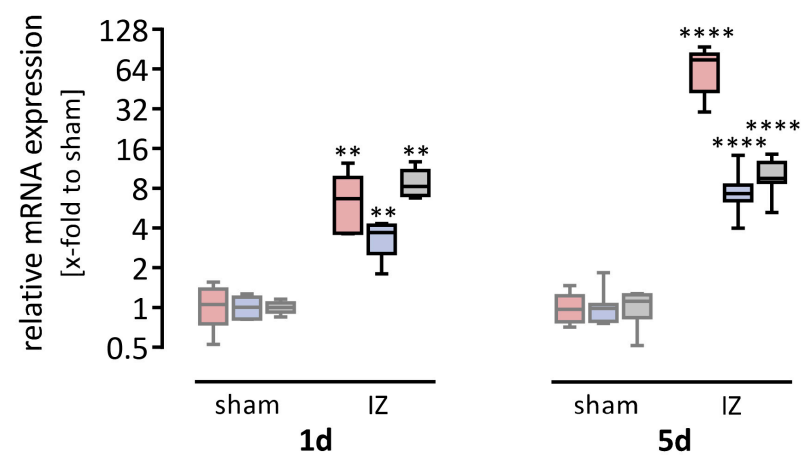

Cellular origin of MIF receptors

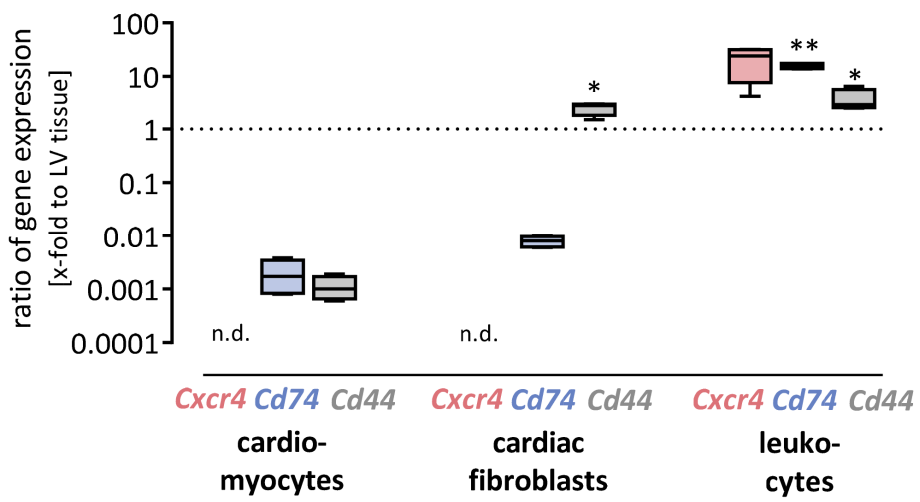

Figure 2. MIF receptors $C x c r 4$ and $C d 74 / C d 44$ are expressed in cardiac tissue and upregulated after MI as a result of recruited leukocytes. (A) MIF and MIF-2 can bind to the G protein-coupled receptor CXCR4 (red) as well as the heterodimer CD74/CD44 (blue/grey) leading to different intracellular signaling. (B) The gene expression levels of all three transmembrane proteins were highly increased after myocardial infarction. Gene expression levels are shown as relative mRNA expression (x-fold to sham operated mice) using the formula $2^{-\Delta \Delta C t}$ and presented in box plots (min to max). Gene expression data represent 6-8 sham operated mice and 5-11 mice with MI. (C) The gene expression levels of all three transmembrane proteins were determined in healthy LV tissue collected from mice after sham operation. While the expression of $C x c r 4$ is very low, $C d 74$ and $C d 44$ forming the heterodimeric MIF receptor were well expressed in healthy LV tissue. Basal gene expression levels are shown as absolute mRNA expression ( $\mathrm{x}$-fold to the housekeeping gene $\mathrm{Cdkn} 1 \mathrm{~b}$ ) using the formula $2^{-\Delta \mathrm{Ct}}$ and presented in box plots (min to max). (D) The basal gene expression levels of Cxcr4, Cd74 and Cd44 were determined in cardiomyocytes, cardiac fibroblasts and leukocytes. To evaluate the cellular origin of the receptor expression in LV tissue, the ratio between the detected gene expression in the distinct cell type and the expression level in LV tissue was plotted. Those cells with a ratio lower than one contribute less to the receptor expression detected in the whole cardiac tissue. As depicted in red, the Cxcr 4 receptor is not expressed in both resident cardiac cell types, cardiomyocytes and cardiac fibroblasts, whereas leukocytes were the main source of Cxcr4 within the LV tissue. The gene expression of the heterodimeric receptor $C d 74 / C d 44$, depicted in blue and grey, showed that cardiomyocytes, cardiac fibroblasts and leukocytes express both receptor components. While leukocytes are the main source of $C d 74$ expression, $C d 44$ is well expressed in leukocytes and additionally in cardiac fibroblasts, both highly abundant in the infarct zone after MI. * significantly different compared with sham operated mice $\left(\right.$ B) or cardiomyocytes (D). ${ }^{*} p<0.05 ;{ }^{* *} p<0.01{ }^{* * * *} p<0.0001$. 
3.3. Macrophage Migration Inhibitory Factor is Expressed in Murine Left Ventricular Tissue and Upregulated in Activated Cardiac Cells

While Mif and Mif-2 had minor differences in expression levels in the LV tissue, distinct differences occurred identifying their origin. To determine the cellular source within the cardiac tissue, basal gene expression of Mif and Mif-2 was measured in the LV tissue from healthy mice as well as in different cardiac cell types including cardiomyocytes, cardiac fibroblasts and leukocytes. To compare the gene expression, data are plotted as absolute mRNA expression $x$-fold to the housekeeping gene $C d k n 1 b$ and compared with the expression determined in LV tissue. As shown in Figure 3A, similar Mif expression levels were determined in cardiac fibroblasts (1.2 \pm 0.2 -fold to Cdkn1b) and leukocytes (1.2 \pm 0.6-fold to $C d k n 1 b)$ compared with LV tissue (2.5 \pm 0.3 -fold to $C d k n 1 b)$, whereas significantly lower Mif expression was found in cardiomyocytes $(0.7 \pm 0.2$-fold to $C d k n 1 b)$. In contrast, Mif-2 expression in cardiomyocytes $(0.16 \pm 0.03$-fold to $C d k n 1 b)$, cardiac fibroblasts $(0.41 \pm 0.08$-fold to $C d k n 1 b)$ and leukocytes $(0.13 \pm 0.02$-fold to $C d k n 1 b)$ was significantly lower compared with LV tissue $(1.4 \pm 0.1$-fold to $C d k n 1 b)$. Accordingly, the investigated cardiac cell types did not represent the main source of cardiac Mif-2 expression. Since Mif but not Mif-2 was upregulated during acute MI, we further investigated different external stimuli to activate cardiomyocytes, cardiac fibroblasts and leukocytes detected as one cellular source of Mif within the LV tissue.

To further characterize Mif gene expression and its cellular origin, different stimuli were applied to cardiomyocytes, cardiac fibroblasts and leukocytes. Therefore, gene expression levels of Mif were assessed in cultured cardiomyocytes and cardiac fibroblasts exposed to simulated ischemia. As shown in Figure 3B,C, simulated ischemia induced Mif gene expression after $24 \mathrm{~h}$ in cardiomyocytes $(3.6 \pm 0.4$-fold $)$ as well as in cardiac fibroblasts $(6.0 \pm 0.5$-fold). These findings are in line with the increased gene expression levels of Mif detected after myocardial infarction in mice (Figure 1A).

Next, we investigated whether mechanical stretch mimicking dilation of the cardiac ventricle post-MI influences Mif gene expression. Therefore, we applied cyclic mechanical stretch with an elongation of $10 \%$ and a frequency of $1 \mathrm{~Hz}$ to cultured cardiomyocytes and cardiac fibroblasts. As shown in Figure 3B,C, mechanical stretch significantly induced Mif gene expression after $6 \mathrm{~h}$ in cardiomyocytes $(2.2 \pm 0.5$-fold) and cardiac fibroblasts $(4.2 \pm 0.7$-fold) compared with the respective untreated control cells.

Moreover, during MI, cardiac fibroblasts are exposed to different pro-inflammatory and pro-fibrotic stimuli. Thus, we used TNF- $\alpha$ as a pro-inflammatory cytokine and TGF- $\beta$ as a pro-fibrotic cytokine to stimulate cardiac fibroblasts. Subsequent gene expression analysis of stimulated cardiac fibroblasts revealed an effect of the recombinant TNF- $\alpha$ as well as TGF- $\beta$ on the expression of Mif. As shown in Figure 3C, the pro-inflammatory cytokine TNF- $\alpha$ (4.2 \pm 1.0 -fold) as well as the pro-fibrotic growth factor TGF- $\beta$ ( $4.8 \pm 1.2$-fold) led to elevated Mif expression.

Since we identified leukocytes as another source of MIF, we next aimed to investigate Mif expression in activated leukocytes. Therefore, cell culture supernatant derived from cardiac fibroblasts exposed to simulated ischemia was collected. Subsequently, isolated splenocytes representing invading leukocytes were activated using this conditioned medium followed by gene expression analysis. As visualized in Figure 3D, activated leukocytes revealed significantly higher gene expression levels of Mif $(2.3 \pm 0.4$-fold) compared with untreated control cells. 
A

Cellular origin of Mif and Mif-2

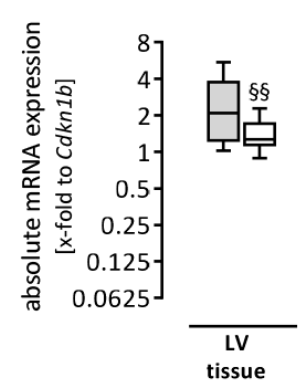

$\square$ Mif $\square$ Mif-2

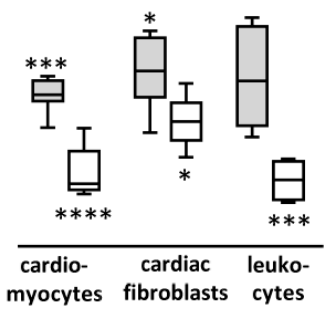

\section{B}

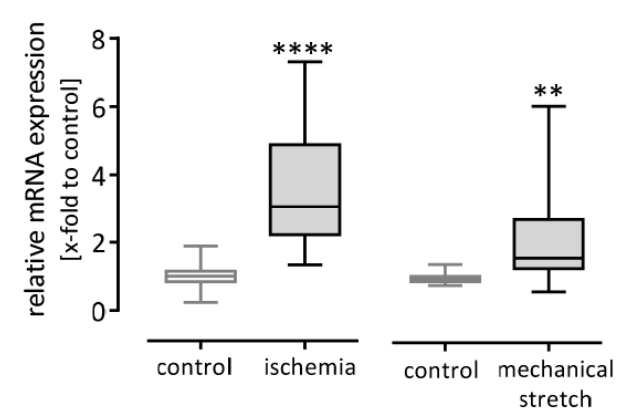

D Mif in activated

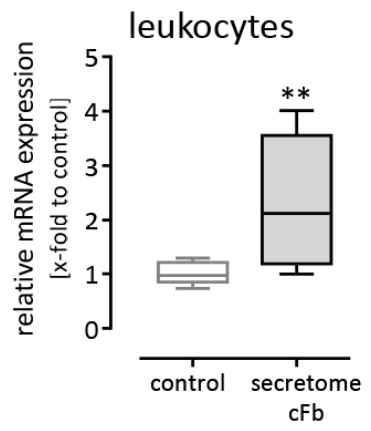

C Mif in activated cardiac fibroblasts
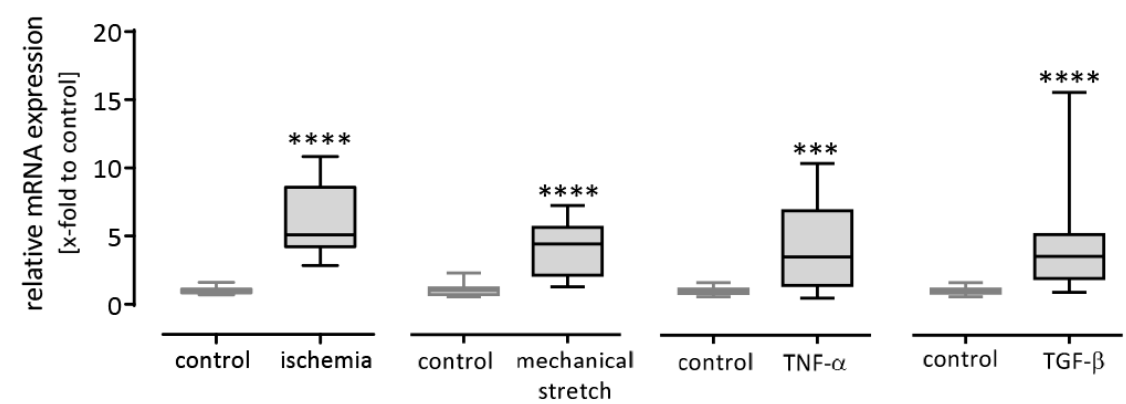

Figure 3. Mif is expressed in cardiac cells and upregulated after activation. (A) Basal gene expression of Mif and Mif-2 was determined in LV tissue and individual cell cultures. Cardiac fibroblasts and leukocytes exhibited similar Mif expression compared with LV tissue, whereas cardiomyocytes expressed significantly less Mif. While Mif and Mif-2 revealed similar expression levels in the LV tissue, considerably less Mif-2 was determined in the investigated cardiac cell types representing not the main source of cardiac Mif-2. (B) Cultured cardiomyocytes were activated by simulated ischemia for $24 \mathrm{~h}$ (D-glucose was replaced by L-glucose and oxygen was reduced to $1 \%$ ) or mechanically stretched with $10 \%$ elongation at a frequency of $1 \mathrm{~Hz}$ for $6 \mathrm{~h}$. Ischemia as well as mechanical stretch induced Mif gene expression in cardiomyocytes. (C) Cardiac fibroblasts were exposed to simulated ischemia for $24 \mathrm{~h}$ or to mechanical stretch $(10 \%$ elongation, $1 \mathrm{~Hz})$ for $6 \mathrm{~h}$. Both external stimuli resulted in increased Mif expression. Moreover, cardiac fibroblasts were stimulated with $10 \mathrm{ng} / \mathrm{mL}$ TNF- $\alpha$ or $5 \mathrm{ng} / \mathrm{mL}$ TGF- $\beta$ for $6 \mathrm{~h}$ which led to increased gene expression levels of Mif. (D) Leukocytes were activated with cell culture supernatant derived from cardiac fibroblasts exposed to simulated ischemia. This conditioned medium induced the gene expression of Mif in leukocytes after $24 \mathrm{~h}$. Basal gene expression levels are shown as absolute mRNA expression ( $\mathrm{x}$-fold to the housekeeping gene $C d k n 1 b$ ) using the formula $2^{-\Delta \mathrm{Ct}}$ and presented in box plots ( $\mathrm{min}$ to max). Alteration of gene expression is depicted as relative mRNA expression ( $x$-fold to control cells) using the formula $2^{-\Delta \Delta \mathrm{Ct}}$. Gene expression data represent 2-8 independent experiments, each performed in 4-8 replicates. * significantly different compared with LV tissue or untreated cells as control; ${ }^{*} p<0.05$; $^{* *} p<0.01$; ${ }^{* * *} p<0.001$; ${ }^{* * *} p<0.0001$. $\S$ significantly different compared with Mif expression in LV tissue; $\S \S p<0.01$. 
3.4. Recombinant Macrophage Migration Inhibitory Factor Induced Paracrine Effects on Cardiac Fibroblasts but Not on Cardiomyocytes

As shown in Figures 1 and 3, Mif expression is induced by MI in cardiac tissue and by various external stimuli in different cardiac cell types. Next, we aimed to identify possible paracrine or autocrine effects of MIF protein regarding cardiac inflammation. Therefore, cardiomyocytes as well as cardiac fibroblasts were stimulated with $50 \mathrm{ng} / \mathrm{mL}$ recombinant MIF protein for $24 \mathrm{~h}$ followed by gene expression analysis. First, we examined whether MIF stimulation can in turn induce Mif gene expression in cardiomyocytes and cardiac fibroblasts. As shown in Figure 4A, cardiac fibroblasts but not cardiomyocytes increased Mif expression after MIF stimulation and therefore may amplify the effects of MIF secreted by different cardiac cell types.
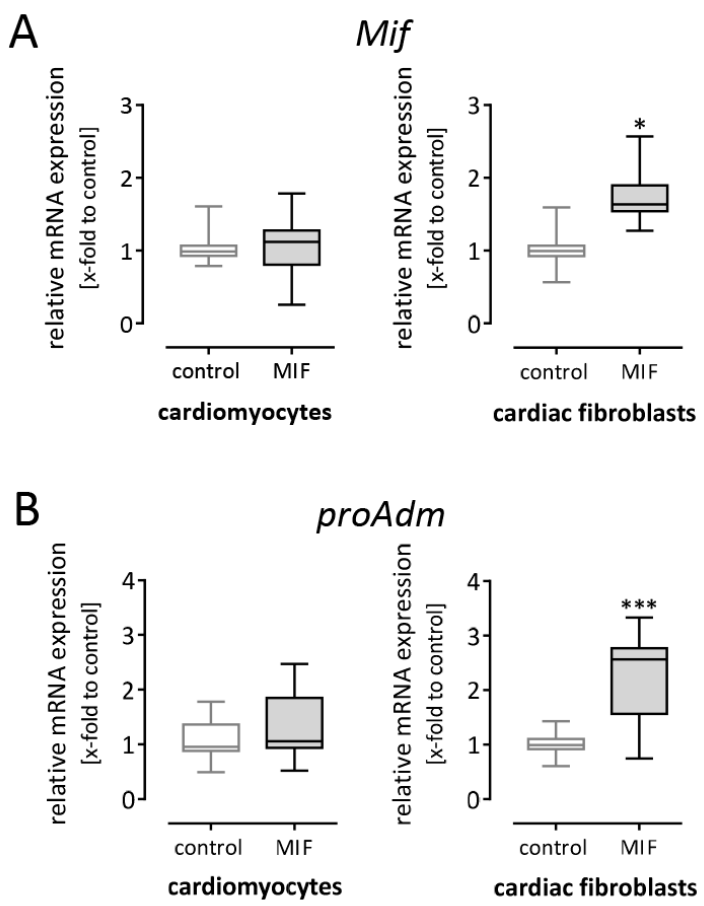

proAdm
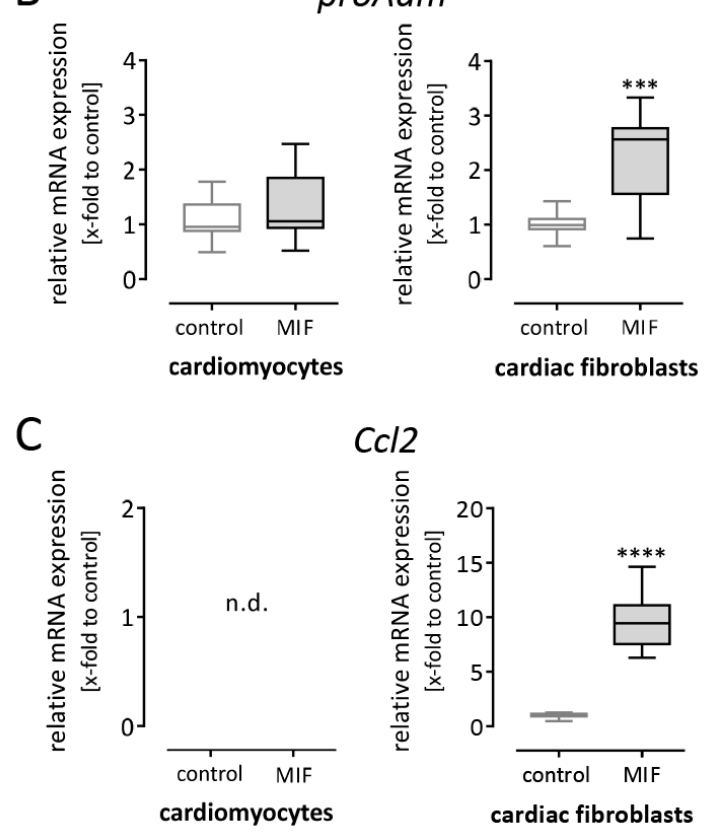

Figure 4. Recombinant MIF stimulates pro-inflammatory response in cardiac fibroblasts but not in cardiomyocytes. Cardiomyocytes and cardiac fibroblasts were stimulated with $50 \mathrm{ng} / \mathrm{mL}$ recombinant MIF for $24 \mathrm{~h}$ followed by gene expression analysis. (A) After MIF stimulation, cardiomyocytes did not alter the gene expression of Mif, whereas in cardiac fibroblasts MIF stimulation in turn increased the gene expression of Mif and may amplify its effects. (B) The expression of proAdm was not significantly increased in cardiomyocytes but in cardiac fibroblasts. (C) The pro-inflammatory chemokine Ccl2 was not detectable in cardiomyocytes. In contrast, cardiac fibroblasts respond to MIF stimulation with highly increased $\mathrm{Ccl} 2$ expression. Gene expression levels are shown as relative mRNA expression ( $\mathrm{x}$-fold to control cells) using the formula $2^{-\Delta \Delta C t}$ and presented in box plots (min to max). Gene expression data represent three independent experiments, each performed in 6-12 replicates. * significantly different compared with untreated cells as control; ${ }^{*} p<0.05 ;{ }^{* * *} p<0.001 ;{ }^{* * *} p<0.0001 ;$ n.d. not detectable. 
Further, we investigated the paracrine or autocrine effects of MIF on cardiomyocytes and cardiac fibroblasts regarding inflammation. After MIF stimulation, gene expression of pro-inflammatory proAdm and $\mathrm{Ccl} 2$ was analyzed. As shown in Figure 4B,C, gene expression levels of proAdm $(2.3 \pm 0.2$-fold to $C d k n 1 b)$ and $C c l 2(9.6 \pm 0.5$-fold to $C d k n 1 b)$ were significantly elevated in cardiac fibroblasts after MIF stimulation. In contrast, in cardiomyocytes, increased proAdm expression was not determined and the expression of the chemokine $\mathrm{C} c \mathrm{l} 2$ was not detectable. Altogether, cardiomyocytes did not respond to MIF stimulation, whereas cardiac fibroblasts amplified Mif expression and increased their expression of pro-inflammatory cytokines.

\subsection{Gene Expression in Cardiac Fibroblasts is Altered after Stimulation with Macrophage Migration Inhibitory Factor and Simulated Ischemia}

As shown in Figure 3, simulated ischemia induced Mif expression in cardiomyocytes, as well as in cardiac fibroblasts. In contrast, MIF stimulation in turn induced pro-inflammatory gene expression in cardiac fibroblasts but not in cardiomyocytes (Figure 4). Therefore, we further examined cardiac fibroblasts regarding the effects of ischemia in the presence or absence of recombinant MIF protein to uncover possible paracrine effects of MIF during MI.

A
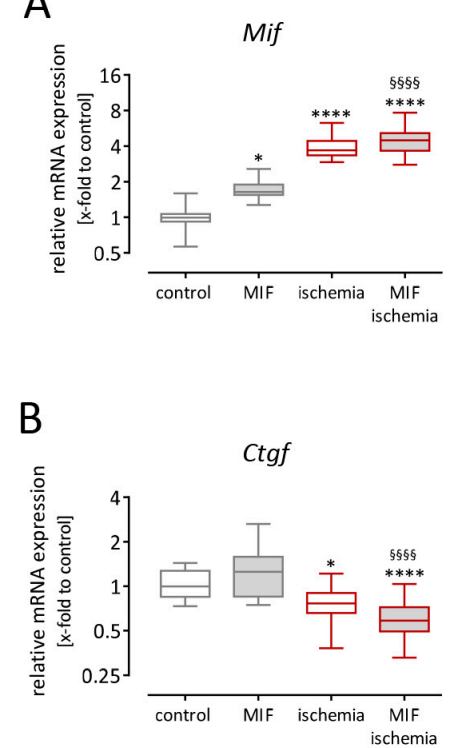
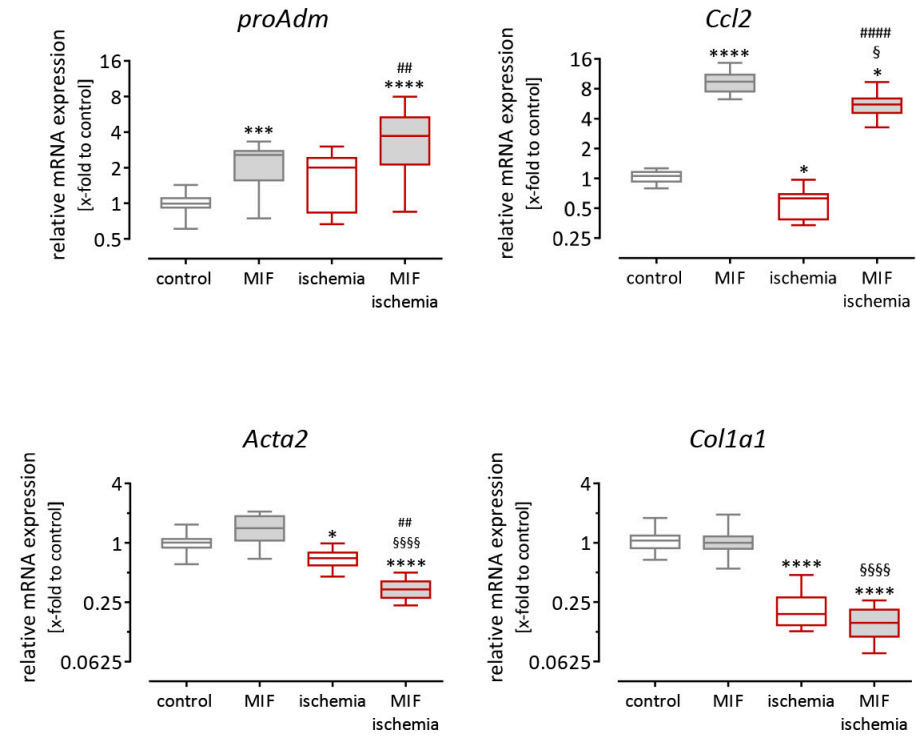

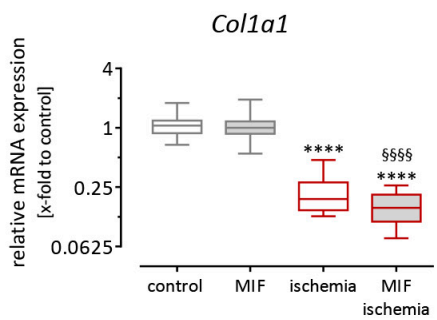

Figure 5. Pro-inflammatory and fibrotic signaling in cardiac fibroblasts exposed to ischemia in the presence of MIF. Murine cardiac fibroblasts were stimulated using $50 \mathrm{ng} / \mathrm{mL}$ recombinant murine MIF or simulated ischemia for $24 \mathrm{~h}$. (A) Pro-inflammatory gene expression of Mif, proAdm and Ccl2 was quantified. The expression of Mif and proAdm was increased by stimulation using recombinant MIF and simulated ischemia. The combination of both stimuli revealed additive effects and the gene expression was further increased. The expression of $\mathrm{Ccl} 2$ was increased by stimulation using recombinant MIF but decreased by ischemia. Combining both stimuli, the MIF-induced Ccl2 expression was attenuated by applying ischemia. (B) MIF stimulation did not alter the expression of the fibrotic genes Ctgf, Acta2 and Col1a1, whereas the gene expression was significantly reduced during simulated ischemia. The combination of both stimuli resulted in further reduced expression levels. Data from cardiac fibroblasts under simulated ischemic conditions are plotted with red borders. Additional treatment is indicated using grey-filled bars. Gene expression levels are shown as relative mRNA expression (x-fold to control cells) using the formula $2^{-\Delta \Delta \mathrm{Ct}}$ and presented in box plots (min to max). Gene expression data represent 3 independent experiments, each performed in 6-12 replicates. * significantly different compared with untreated cells as control; ${ }^{*} p<0.05 ;{ }^{* * *} p<0.001 ;{ }^{* * * *} p<0.0001$. $\S$ significantly different compared with MIF; $\S p<0.05$; $\S \S \S p<0.0001$. \# significantly different compared with ischemia; \#\# $p<0.01$; \#\#\# $p<0.0001$. 
Cardiac fibroblasts were exposed to $50 \mathrm{ng} / \mathrm{mL}$ recombinant MIF alone and to simulated ischemia in the presence or absence of recombinant MIF for $24 \mathrm{~h}$. Subsequently, gene expression levels of inflammatory and fibrotic genes were analyzed. As shown in Figure 5A, recombinant MIF resulted in increased gene expression levels of the pro-inflammatory mediators Mif, proAdm and Ccl2. While Mif and pro $A d m$ expression was approximately 2-fold greater, the enhancement of $C c l 2$ expression reached 10-fold compared with untreated cells. Next, we examined the influence of ischemia alone. As shown in Figure 5A, Mif expression was 4-fold greater and therefore even higher compared with stimulation using recombinant MIF. Furthermore, the expression of proAdm was slightly but not significantly increased during ischemia. In contrast, ischemia resulted in significantly reduced expression of $\mathrm{Ccl} 2$ revealing the opposite impact of MIF protein stimulation. Simulated ischemia in the presence of recombinant MIF protein triggered additive effects in cardiac fibroblasts. While the expression of Mif and proAdm was further increased, the expression of Ccl2 was attenuated from 9.6-fold increased expression after MIF stimulation to 5.6-fold increased expression after ischemia in the presence of MIF.

As shown in Figure 5B, we further examined the expression of pro-fibrotic genes in cardiac fibroblasts, namely Ctgf, Acta2 and Col1a1. Using recombinant MIF to stimulate cardiac fibroblasts, no altered pro-fibrotic gene expression was found. In contrast, simulated ischemia reduced the expression of Ctgf, Acta2 and Col1a1 in cardiac fibroblasts. While MIF stimulation itself had no influence on pro-fibrotic gene expression, simulated ischemia in the presence of recombinant MIF revealed a further reduction of pro-fibrotic gene expression compared with ischemia in the absence of MIF.

\section{Discussion}

Since MIF is known as a pleiotropic cytokine, it is involved in several inflammatory diseases such as MI. In mice, gene and protein expression of MIF increased during the acute phase of MI. This was associated with increased expression of other pro-inflammatory cytokines such as $\operatorname{Tnf}-\alpha$ and $C c l 2$, representing the inflammatory phase. Our in vitro experiments revealed that cardiomyocytes as well as cardiac fibroblasts increased Mif expression during simulated ischemia and other external stimuli. Utilizing recombinant MIF protein, pro-inflammatory effects were identified in cardiac fibroblasts but not in cardiomyocytes. Since MIF in turn induced gene expression of Mif in cardiac fibroblasts, they may amplify the cardio-protective function of MIF on cardiomyocytes.

\subsection{Cardio-Protective Function of Macrophage Migration Inhibitory Factor}

The function of MIF during MI is complex, as well as time dependent [38]. Especially during acute ischemia, MIF mediates cardio-protection mainly through the CD74/CD44 receptor complex utilizing several mechanisms: AMPK activation leading to increased glucose uptake [31], inhibiting JNK to suppress apoptotic signaling [39] and reducing oxidative stress [40]. In line with these findings, using an ischemia/reperfusion model (15 min ischemia/4 h reperfusion), MIF deficient mice revealed increased infarct sizes [31]. Despite its cardio-protective functions, in a prolonged ischemia/reperfusion model (60 min ischemia/24 h reperfusion), MIF deficiency reduced infarct sizes and cardiomyocyte apoptosis since the inflammatory response was suppressed in MIF KO mice. In other cardiac diseased models, such as pressure overload-induced cardiac hypertrophy [41], diabetic cardiomyopathy induced by type 1 diabetes [42] and doxorubicin-induced cardiomyopathy [43], MIF deficiency exacerbated the impaired cardiac function and lead to increased mortality. These studies emphasize the cardio-protective function of MIF in the absence of aggravating cardiac inflammation. Besides its structural similarities to MIF, MIF-2 binds to the CD74/CD44 receptor complex and recapitulates all important actions of MIF [8,26,27]. In our MI mouse model opposing expression levels were determined after MI. Therefore, we suggest no crucial cardio-protective role of MIF-2 during acute MI. 


\subsection{Cellular Origin of Macrophage Migration Inhibitory Factor after Myocardial Infarction}

Myocardial infarction patients are known to have elevated plasma levels of MIF, which are predictive for infarct size [30], but the molecular actions of MIF and its role during MI remain unclear. In our experiments, we first determined the basal expression of Mif in cardiac cells including cardiomyocytes, cardiac fibroblasts and splenocytes representing a variety of leukocytes. Compared with the Mif expression in healthy LV tissue, similar expression levels were found in cardiac fibroblasts as well as in leukocytes, whereas cardiomyocytes exhibited minor Mif expression. The structurally related Mif-2 was expressed to a slightly lower extent in healthy LV tissue compared to Mif. The cells investigated here exhibited considerably less Mif-2 expression suggesting other additional sources. Less is known about the role of MIF-2 in diseased animal models, but regarding our data, we suggest an inferior impact compared to MIF.

Next, we exposed the investigated cell types to different external stimuli. During simulated ischemia Mif expression increased in cardiomyocytes and cardiac fibroblasts. Furthermore, to mimic MI, conditioned medium derived from cardiac fibroblasts exposed to ischemia was used to activate leukocytes resulting in increased Mif expression as well. It was already reported that long term chronic hypoxia induces Mif expression in rat cardiomyocytes [20]. Regarding our results, Mif expression during MI is not only caused by cardiomyocytes, but more prominently by cardiac fibroblasts. In addition to simulated ischemic conditions we applied both cardiac cell types, cardiomyocytes and cardiac fibroblasts, to mechanical stretch mimicking post-MI cardiac dilation. Interestingly, both cell types increased Mif expression as a result of mechanical stretch.

It is well known that during the acute phase after MI, inflammatory cells invade the injured myocardium. Therefore, we stimulated cardiac fibroblasts with TNF- $\alpha$ and TGF- $\beta$ known to be secreted by activated immune cells. Both proteins led to increased Mif expression in cardiac fibroblasts. Since cardiac fibroblasts express Mif to a higher extent, increased Mif expression during MI might be caused by ischemia on the one hand and by subsequently developed cardiac inflammation on the other hand.

\subsection{Macrophage Migration Inhibitory Factor and Cardiac Inflammation after Myocardial Infarction}

In general, MIF is known as a pleiotropic cytokine and this might be applicable to MIF-2 as well $[8,26]$. Despite its cardio-protective functions, MIF deficiency becomes beneficial when cardiac inflammation contributes to myocardial injury. After prolonged and severe ischemia/reperfusion injury, reduced cytokine expression and less leukocyte infiltration was observed in Mif $^{-/-}$mice compared to wild-type (WT) [32]. Macrophage Migration Inhibitory Factor itself can elicit leukocyte recruitment through the CXCR2/4 receptors [23]. Macrophages derived from WT mice migrate towards homogenized infarct tissue from WT. This effect was significantly reduced in response to homogenized infarct tissue from $\mathrm{Mif}^{-/-}$mice, demonstrating less chemokine expression in $\mathrm{Mif}^{-/-}$ mice after MI. Interestingly, when $\mathrm{Mif}^{-/-}$macrophages were exposed to WT infarct tissue, migration was also lower than WT macrophages [44].

In contrast to increased Mif expression levels during the acute phase after MI, characterized by arising cardiac inflammation, Mif-2 expression was significantly decreased. These data suggest complementary effects on inflammation, but so far, nothing is known about the function of MIF-2 during MI. In line with our observation, Mif-2 expression was decreased in inflammatory adipose tissue compared with healthy controls [45], whereas Mif expression was increased and may mediate the recruitment of inflammatory cells [46]. In mice, macrophage recruitment was induced by lipopolysaccharide (LPS) injection and was further increased when MIF was injected additionally. In contrast, additional injection of MIF-2 does not lead to further increased macrophage recruitment compared with LPS injection alone. Regarding our data, we suggest that MIF-2 does not contribute to the development of cardiac inflammation.

Besides its own chemoattractant properties, recombinant MIF induced chemokine expression in cardiac fibroblasts rather than provoking expression of matrix proteins required for scar stabilization 
after MI. On cardiac fibroblasts, MIF led to increased chemokine expression promoting leukocyte recruitment on the one hand, but in turn induced Mif expression itself serving as cardio-protection on cardiomyocytes on the other hand (Figure 6). Since circulating MIF directly facilitates leukocyte recruitment towards inflammation, MIF represents a suitable target to avoid major adverse effects. Using a MIF-neutralizing antibody, macrophage and T-cell content were reduced in atherosclerotic plaques [23].

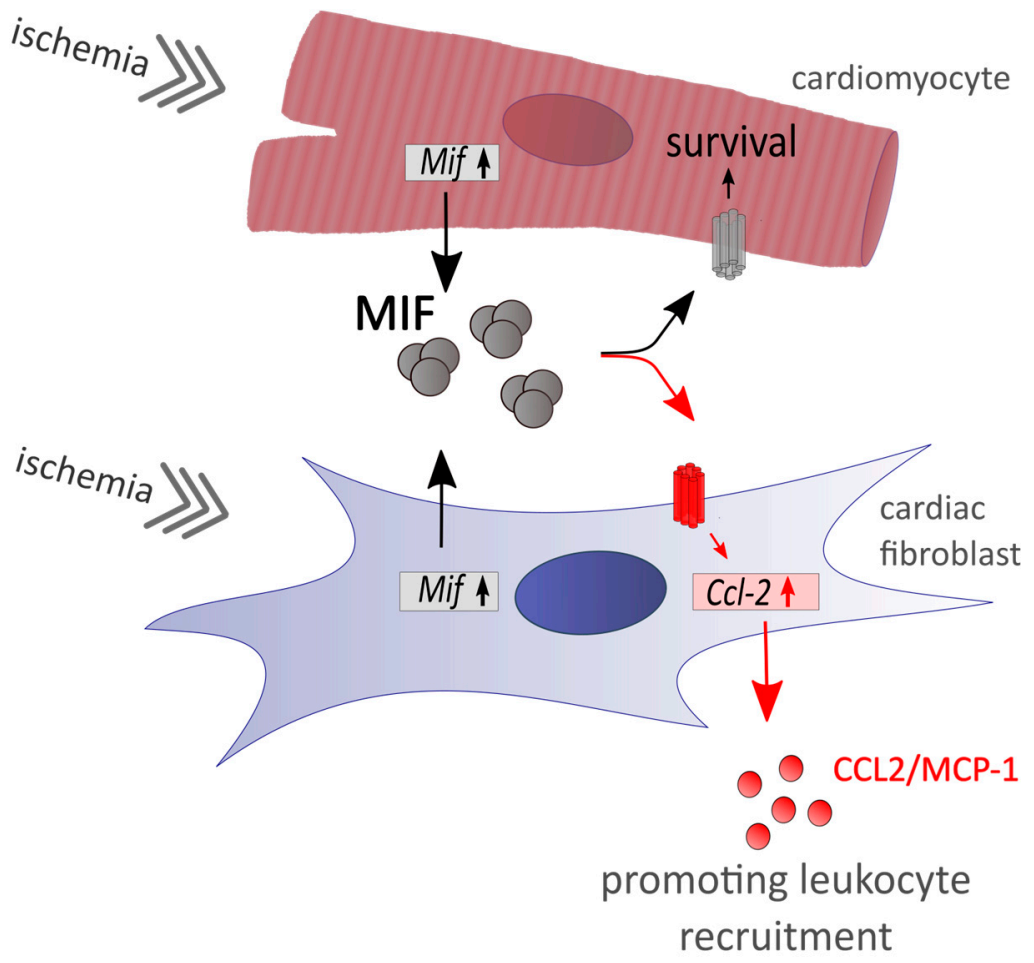

Figure 6. While ischemia induces Mif expression in both cardiac cell types, cardiomyocytes and cardiac fibroblasts, secreted MIF protein revealed different functions. Well characterized cardio-protective effects of MIF are only identified in cardiomyocytes, whereas cardiac fibroblasts may serve as sentinel cells to promote the pro-inflammatory effect of MIF by expressing chemoattractive chemokines.

4.4. Macrophage Migration Inhibitory Factor-Utilizing Its Cardio-Protective Function but Treating the Pro-Inflammatory Function?

Macrophage Migration Inhibitory Factor shows cardio-protective functions but provokes cardiac inflammation which in turn is known to be detrimental for the myocardial tissue after MI. Since MIF deficiency becomes beneficial regarding cardiac inflammation, anti-MIF interventions might be a potential therapeutic option following MI [5]. Anti-MIF intervention using a MIF antagonist significantly reduced the incidence of cardiac rupture that occurred at 3-4 days after MI [5]. Other inflammatory diseases also benefit from administration of anti-MIF antibodies. In mice subjected to peritonitis sepsis, administration of anti-MIF antibodies could significantly increase the survival rate [47].

Since inflammatory response is essential for the subsequent healing processes, identifying the extent and time frame of anti-inflammatory treatments is still a great challenge [5].

\section{Conclusions}

The presented data show that MIF was expressed by resident cardiac cells during MI. In vitro, Mif expression was induced by different external stimuli in cardiomyocytes and cardiac fibroblasts. Addition of recombinant MIF protein increased the expression of pro-inflammatory genes in cardiac fibroblasts including Mif expression itself. Thereby, cardiac fibroblasts may amplify Mif expression 
during ischemia supporting cardiomyocyte survival, but increased chemokine expression may promote leukocyte recruitment leading to aggravated cardiac inflammation.

Author Contributions: Conceptualization, S.V., S.K. and D.L.; Methodology, S.V., S.K., K.S. and S.W.; Formal Analysis, S.V. and S.K.; Investigation, S.V., S.K, S.W., M.S., B.S. and D.L.; Resources, S.W., M.S., B.S., E.G. and D.L.; Data Curation, S.V., S.K., K.S., M.S.; Writing-Original Draft Preparation, S.V. and S.K.; Writing-Review \& Editing, D.L., K.S., E.G., C.M., S.B., D.W.; Visualization, S.V., S.K. and D.L.; Supervision, S.B., D.W. and D.L.; Project Administration, D.L.; Funding Acquisition, D.W. and D.L.

Funding: This research was funded by the German Ministry of Research and Education (DZHK, German Center of Cardiovascular Research), grant number 81365-150.

Acknowledgments: The authors thank Mareile Schröder and Hartwig Wiebold for their excellent technical support. Furthermore, the authors thank the UKE Microscope Imaging Facility [Umif]. The presented study was supported by the German Ministry of Research and Education (DZHK, German Center of Cardiovascular Research).

Conflicts of Interest: The authors declare no conflict of interest.

\section{References}

1. Thygesen, K.; Alpert, J.S.; Jaffe, A.S.; Simoons, M.L.; Chaitman, B.R.; White, H.D.; Thygesen, K.; Alpert, J.S.; White, H.D.; Jaffe, A.S.; et al. Third universal definition of myocardial infarction. Eur. Heart J. 2012, 33, 2551-2567. [CrossRef] [PubMed]

2. Lopez, A.D.; Mathers, C.D.; Ezzati, M.; Jamison, D.T.; Murray, C.J. Global and regional burden of disease and risk factors, 2001: Systematic analysis of population health data. Lancet 2006, 367, 1747-1757. [CrossRef]

3. Frangogiannis, N.G. The inflammatory response in myocardial injury, repair, and remodelling. Nat. Rev. Cardiol. 2014, 11, 255-265. [CrossRef] [PubMed]

4. Hinrichs, S.; Scherschel, K.; Kruger, S.; Neumann, J.T.; Schwarzl, M.; Yan, I.; Warnke, S.; Ojeda, F.M.; Zeller, T.; Karakas, M.; et al. Precursor proadrenomedullin influences cardiomyocyte survival and local inflammation related to myocardial infarction. Proc. Natl. Acad. Sci. USA 2018, 115, E8727-E8736. [CrossRef] [PubMed]

5. White, D.A.; Fang, L.; Chan, W.; Morand, E.F.; Kiriazis, H.; Duffy, S.J.; Taylor, A.J.; Dart, A.M.; Du, X.J.; Gao, X.M. Pro-inflammatory action of MIF in acute myocardial infarction via activation of peripheral blood mononuclear cells. PLoS ONE 2013, 8, e76206. [CrossRef]

6. $\quad$ Lindner, D.; Zietsch, C.; Tank, J.; Sossalla, S.; Fluschnik, N.; Hinrichs, S.; Maier, L.; Poller, W.; Blankenberg, S.; Schultheiss, H.P.; et al. Cardiac fibroblasts support cardiac inflammation in heart failure. Basic Res. Cardiol. 2014, 109, 428. [CrossRef] [PubMed]

7. Westermann, D.; Lindner, D.; Kasner, M.; Zietsch, C.; Savvatis, K.; Escher, F.; von Schlippenbach, J.; Skurk, C.; Steendijk, P.; Riad, A.; et al. Cardiac inflammation contributes to changes in the extracellular matrix in patients with heart failure and normal ejection fraction. Circ. Heart Fail. 2011, 4, 44-52. [CrossRef] [PubMed]

8. Tilstam, P.V.; Qi, D.; Leng, L.; Young, L.; Bucala, R. MIF family cytokines in cardiovascular diseases and prospects for precision-based therapeutics. Expert Opin. Ther. Targets 2017, 21, 671-683. [CrossRef]

9. van Zuylen, V.L.; den Haan, M.C.; Geutskens, S.B.; Roelofs, H.; Fibbe, W.E.; Schalij, M.J.; Atsma, D.E. Post-myocardial infarct inflammation and the potential role of cell therapy. Cardiovasc. Drugs Ther. 2015, 29, 59-73. [CrossRef]

10. Lolis, E.; Bucala, R. Crystal structure of macrophage migration inhibitory factor (MIF), a glucocorticoid-induced regulator of cytokine production, reveals a unique architecture. Proc. Assoc. Am. Physicians 1996, 108, 415-419.

11. Muhlhahn, P.; Bernhagen, J.; Czisch, M.; Georgescu, J.; Renner, C.; Ross, A.; Bucala, R.; Holak, T.A. NMR characterization of structure, backbone dynamics, and glutathione binding of the human macrophage migration inhibitory factor (MIF). Protein Sci. 1996, 5, 2095-2103. [CrossRef] [PubMed]

12. Baugh, J.A.; Chitnis, S.; Donnelly, S.C.; Monteiro, J.; Lin, X.; Plant, B.J.; Wolfe, F.; Gregersen, P.K.; Bucala, R. A functional promoter polymorphism in the macrophage migration inhibitory factor (MIF) gene associated with disease severity in rheumatoid arthritis. Genes Immun. 2002, 3, 170-176. [CrossRef] [PubMed]

13. Calandra, T.; Echtenacher, B.; Roy, D.L.; Pugin, J.; Metz, C.N.; Hultner, L.; Heumann, D.; Mannel, D.; Bucala, R.; Glauser, M.P. Protection from septic shock by neutralization of macrophage migration inhibitory factor. Nat. Med. 2000, 6, 164-170. [CrossRef] [PubMed] 
14. Morand, E.F.; Bucala, R.; Leech, M. Macrophage migration inhibitory factor: An emerging therapeutic target in rheumatoid arthritis. Arthritis Rheum. 2003, 48, 291-299. [CrossRef] [PubMed]

15. Morand, E.F.; Leech, M.; Bernhagen, J. MIF: A new cytokine link between rheumatoid arthritis and atherosclerosis. Nat. Rev. Drug Discov. 2006, 5, 399-410. [CrossRef] [PubMed]

16. David, J.R. Delayed hypersensitivity in vitro: Its mediation by cell-free substances formed by lymphoid cell-antigen interaction. Proc. Natl. Acad. Sci. USA 1966, 56, 72-77. [CrossRef] [PubMed]

17. Bloom, B.R.; Bennett, B. Mechanism of a reaction in vitro associated with delayed-type hypersensitivity. Science 1966, 153, 80-82. [CrossRef]

18. Takahashi, M.; Nishihira, J.; Shimpo, M.; Mizue, Y.; Ueno, S.; Mano, H.; Kobayashi, E.; Ikeda, U.; Shimada, K. Macrophage migration inhibitory factor as a redox-sensitive cytokine in cardiac myocytes. Cardiovasc. Res. 2001, 52, 438-445. [CrossRef]

19. Roger, T.; David, J.; Glauser, M.P.; Calandra, T. MIF regulates innate immune responses through modulation of Toll-like receptor 4. Nature 2001, 414, 920-924. [CrossRef]

20. Jian, Z.; Li, J.B.; Ma, R.Y.; Chen, L.; Zhong, Q.J.; Wang, X.F.; Wang, W.; Hong, Y.; Xiao, Y.B. Increase of macrophage migration inhibitory factor (MIF) expression in cardiomyocytes during chronic hypoxia. Clin. Chim. Acta 2009, 405, 132-138. [CrossRef]

21. Gregory, J.L.; Leech, M.T.; David, J.R.; Yang, Y.H.; Dacumos, A.; Hickey, M.J. Reduced leukocyte-endothelial cell interactions in the inflamed microcirculation of macrophage migration inhibitory factor-deficient mice. Arthritis Rheum. 2004, 50, 3023-3034. [CrossRef] [PubMed]

22. Lan, H.Y.; Bacher, M.; Yang, N.; Mu, W.; Nikolic-Paterson, D.J.; Metz, C.; Meinhardt, A.; Bucala, R.; Atkins, R.C. The pathogenic role of macrophage migration inhibitory factor in immunologically induced kidney disease in the rat. J. Exp. Med. 1997, 185, 1455-1465. [CrossRef] [PubMed]

23. Bernhagen, J.; Krohn, R.; Lue, H.; Gregory, J.L.; Zernecke, A.; Koenen, R.R.; Dewor, M.; Georgiev, I.; Schober, A.; Leng, L. MIF is a noncognate ligand of CXC chemokine receptors in inflammatory and atherogenic cell recruitment. Nat. Med. 2007, 13, 587-596. [CrossRef] [PubMed]

24. Leng, L.; Metz, C.N.; Fang, Y.; Xu, J.; Donnelly, S.; Baugh, J.; Delohery, T.; Chen, Y.; Mitchell, R.A.; Bucala, R. MIF signal transduction initiated by binding to CD74. J. Exp. Med. 2003, 197, 1467-1476. [CrossRef] [PubMed]

25. Shi, X.; Leng, L.; Wang, T.; Wang, W.; Du, X.; Li, J.; McDonald, C.; Chen, Z.; Murphy, J.W.; Lolis, E.; et al. CD44 is the signaling component of the macrophage migration inhibitory factor-CD74 receptor complex. Immunity 2006, 25, 595-606. [CrossRef] [PubMed]

26. Merk, M.; Mitchell, R.A.; Endres, S.; Bucala, R. D-dopachrome tautomerase (D-DT or MIF-2): Doubling the MIF cytokine family. Cytokine 2012, 59, 10-17. [CrossRef] [PubMed]

27. Merk, M.; Zierow, S.; Leng, L.; Das, R.; Du, X.; Schulte, W.; Fan, J.; Lue, H.; Chen, Y.; Xiong, H.; et al. The $D$-dopachrome tautomerase $(D D T)$ gene product is a cytokine and functional homolog of macrophage migration inhibitory factor (MIF). Proc. Natl. Acad. Sci. USA 2011, 108, E577-E585. [CrossRef]

28. Takahashi, M.; Nishihira, J.; Katsuki, T.; Kobayashi, E.; Ikeda, U.; Shimada, K. Elevation of plasma levels of macrophage migration inhibitory factor in patients with acute myocardial infarction. Am. J. Cardiol. 2002, 89, 248-249. [CrossRef]

29. Yu, C.M.; Lau, C.P.; Lai, K.W.; Huang, X.R.; Chen, W.H.; Lan, H.Y. Elevation of plasma level of macrophage migration inhibitory factor in patients with acute myocardial infarction. Am. J. Cardiol. 2001, 88, 774-777. [CrossRef]

30. Chan, W.; White, D.A.; Wang, X.Y.; Bai, R.F.; Liu, Y.; Yu, H.Y.; Zhang, Y.Y.; Fan, F.; Schneider, H.G.; Duffy, S.J.; et al. Macrophage migration inhibitory factor for the early prediction of infarct size. J. Am. Heart Assoc. 2013, 2, e000226. [CrossRef]

31. Miller, E.J.; Li, J.; Leng, L.; McDonald, C.; Atsumi, T.; Bucala, R.; Young, L.H. Macrophage migration inhibitory factor stimulates AMP-activated protein kinase in the ischaemic heart. Nature 2008, 451, 578-582. [CrossRef] [PubMed]

32. Gao, X.M.; Liu, Y.; White, D.; Su, Y.; Drew, B.G.; Bruce, C.R.; Kiriazis, H.; Xu, Q.; Jennings, N.; Bobik, A.; et al. Deletion of macrophage migration inhibitory factor protects the heart from severe ischemia-reperfusion injury: A predominant role of anti-inflammation. J. Mol. Cell. Cardiol. 2011, 50, 991-999. [CrossRef] [PubMed]

33. Rassaf, T.; Weber, C.; Bernhagen, J. Macrophage migration inhibitory factor in myocardial ischaemia/ reperfusion injury. Cardiovasc. Res. 2014, 102, 321-328. [CrossRef] [PubMed] 
34. Westermann, D.; Riad, A.; Lettau, O.; Roks, A.; Savvatis, K.; Becher, P.M.; Escher, F.; Jan Danser, A.H.; Schultheiss, H.P.; Tschope, C. Renin inhibition improves cardiac function and remodeling after myocardial infarction independent of blood pressure. Hypertension 2008, 52, 1068-1075. [CrossRef] [PubMed]

35. Claycomb, W.C.; Lanson, N.A., Jr.; Stallworth, B.S.; Egeland, D.B.; Delcarpio, J.B.; Bahinski, A.; Izzo, N.J., Jr. Hl-1 cells: A cardiac muscle cell line that contracts and retains phenotypic characteristics of the adult cardiomyocyte. Proc. Natl. Acad. Sci. USA 1998, 95, 2979-2984. [CrossRef] [PubMed]

36. Jungen, C.; Scherschel, K.; Eickholt, C.; Kuklik, P.; Klatt, N.; Bork, N.; Salzbrunn, T.; Alken, F.; Angendohr, S.; Klene, C.; et al. Disruption of cardiac cholinergic neurons enhances susceptibility to ventricular arrhythmias. Nat. Commun. 2017, 8, 14155. [CrossRef] [PubMed]

37. Livak, K.J.; Schmittgen, T.D. Analysis of relative gene expression data using real-time quantitative PCR and the $2^{-\Delta \Delta C T}$ method. Methods 2001, 25, 402-408. [CrossRef] [PubMed]

38. Dayawansa, N.H.; Gao, X.M.; White, D.A.; Dart, A.M.; Du, X.J. Role of MIF in myocardial ischaemia and infarction: Insight from recent clinical and experimental findings. Clin. Sci. 2014, 127, 149-161. [CrossRef] [PubMed]

39. Qi, D.; Hu, X.; Wu, X.; Merk, M.; Leng, L.; Bucala, R.; Young, L.H. Cardiac macrophage migration inhibitory factor inhibits JNK pathway activation and injury during ischemia/reperfusion. J. Clin. Investig. 2009, 119, 3807-3816. [CrossRef] [PubMed]

40. Koga, K.; Kenessey, A.; Powell, S.R.; Sison, C.P.; Miller, E.J.; Ojamaa, K. Macrophage migration inhibitory factor provides cardioprotection during ischemia/reperfusion by reducing oxidative stress. Antioxid. Redox Signal. 2011, 14, 1191-1202. [CrossRef] [PubMed]

41. Xu, X.; Hua, Y.; Nair, S.; Bucala, R.; Ren, J. Macrophage migration inhibitory factor deletion exacerbates pressure overload-induced cardiac hypertrophy through mitigating autophagy. Hypertension 2014, 63, 490-499. [CrossRef] [PubMed]

42. Tong, C.; Morrison, A.; Yan, X.; Zhao, P.; Yeung, E.D.; Wang, J.; Xie, J.; Li, J. Macrophage migration inhibitory factor deficiency augments cardiac dysfunction in type 1 diabetic murine cardiomyocytes. J. Diabetes 2010, 2, 267-274. [CrossRef] [PubMed]

43. Xu, X.; Bucala, R.; Ren, J. Macrophage migration inhibitory factor deficiency augments doxorubicin-induced cardiomyopathy. J. Am. Heart Assoc. 2013, 2, e000439. [CrossRef] [PubMed]

44. White, D.A.; Su, Y.; Kanellakis, P.; Kiriazis, H.; Morand, E.F.; Bucala, R.; Dart, A.M.; Gao, X.M.; Du, X.J. Differential roles of cardiac and leukocyte derived macrophage migration inhibitory factor in inflammatory responses and cardiac remodelling post myocardial infarction. J. Mol. Cell. Cardiol. 2014, 69, 32-42. [CrossRef] [PubMed]

45. Kim, B.S.; Tilstam, P.V.; Hwang, S.S.; Simons, D.; Schulte, W.; Leng, L.; Sauler, M.; Ganse, B.; Averdunk, L.; Kopp, R.; et al. D-dopachrome tautomerase in adipose tissue inflammation and wound repair. J. Cell. Mol. Med. 2017, 21, 35-45. [CrossRef] [PubMed]

46. Kim, B.S.; Rongisch, R.; Hager, S.; Grieb, G.; Nourbakhsh, M.; Rennekampff, H.O.; Bucala, R.; Bernhagen, J.; Pallua, N. Macrophage migration inhibitory factor in acute adipose tissue inflammation. PLoS ONE 2015, 10, e0137366. [CrossRef] [PubMed]

47. Kerschbaumer, R.J.; Rieger, M.; Volkel, D.; Le Roy, D.; Roger, T.; Garbaraviciene, J.; Boehncke, W.H.; Mullberg, J.; Hoet, R.M.; Wood, C.R.; et al. Neutralization of macrophage migration inhibitory factor (MIF) by fully human antibodies correlates with their specificity for the beta-sheet structure of MIF. J. Biol. Chem. 2012, 287, 7446-7455. [CrossRef]

(C) 2019 by the authors. Licensee MDPI, Basel, Switzerland. This article is an open access article distributed under the terms and conditions of the Creative Commons Attribution (CC BY) license (http:/ / creativecommons.org/licenses/by/4.0/). 